\section{Questión}

Periodismo / Comunicación ISSN 1669-6581
- Av. $44 \mathrm{~N}^{\circ} 676,1^{\circ}$ piso

CP 1900 - La Plata - Argentina

www.perio.unlp.edu.ar/question

Tiempo de la Peste

Martín Acosta

https://doi.org/10.24215/16696581e396

\title{
Tiempo de la Peste
}

\section{Plague Time}

\author{
Martín Acostai \\ photomartinacosta@gmail.com \\ http://www.martinacosta.com
}

Fotógrafo y docente. Buenos Aires (1960). Su formación originaria en fotografía y periodismo es autodidacta. Actualmente estudia la Licenciatura en Artes Visuales en la UNA y la Diplomatura en Fotografía Social en la UBA.

\section{Enlace}

https://youtu.be/oG1X2uVvOd0

\begin{abstract}
i Se dedica a la fotografía desde 1979. Sus inicios fueron en publicidad en los estudios de Luis de Cesare y Juan Castagnola. Desde 1985 trabaja en periodismo. Ha colaborado para diferentes medios internacionales como The New York Times, Sunday Telegraph, Veja y Abertaren entre otros. Se inició como Reportero Gráfico en la agencia Noticias Argentinas y ha trabajado posteriormente en la agencia Reuters (2019). El diario Página 12 (2014), la revista ADN-Cultura del diario La Nación (2013), El diario La Nación y su revista dominical (2013), en la ONG Greenpeace (2009), el diario Clarín (2006), las revistas Noticias(1990), El Gráfico y el diario Nuevo Sur (1989). Sus coberturas más destacadas en periodismo han sido Reunión G-20 Buenos Aires 2018, Copa América Argentina'11Bolivia'97, crisis del 19 y 20 de diciembre de 2001, Los Juegos Olímpicos de Sydney'00 y Atlanta'96, los mundiales de fútbol de EEUU'94 y Francia'98, La guerra del Cóndor'98, el Juicio por el caso María Soledad Morales'96/97, el caso Carrasco'94, , seguimiento exclusivo de campañas presidenciales de los candidatos Eduardo Angeloz'89, Eduardo Duhalde'99 y Carlos Menem'03 (NA/Clarín), levantamientos militares carapintadas ' $87 / 89$. En el área docente, desarrolla una intensa actividad, dictando cursos, talleres y conferencias. Desde 2007 coordina y dirige su propio Taller de Fotografía Documental (TFD). Director de la Escuela de Fotoperiodismo de la Asociación de Reporteros Gráficos de la Argentina (aRGraescuela), entre 2006 y 2012. Docente en la misma en Fotoperiodismo I desde 2001 hasta la actualidad. Docente en el CCUNGS y en el CCRojas. Participo de Clínicas y Talleres de formación con Sabastiao Salgado, Fred Ritchin, Christian Caujolle, ABBAS, Katty Ryan, Robert Pledge, Pablo Ortiz Monasterio, Ernesto Bazan, Patricia Mendoza, Talleres Travnik, Eduardo Grossman, Diego Goldberg y Miguel Cuarterolo, RES, Carlos Bosch, Mayra Martell, entre otros. En la clínica de artes visuales y análisis de obra de Tulio de Sagastizábal. En el área autoral sus trabajos más destacados son: "Recuperarse" (2018) "Argentina, Crisis, crisis, crisis" (2015), "Daguerromiserias" (2011), "ADN, historias de aparecidos" (2008) y "Menonitas, fin del milenio" (1998). Recibió los premios POYi, Latinoámerica 2011, Primer Premio Adquisición, Concurso Nacional de Fotografía del Ministerio de Defensa, Argentina, 2011. Premio Perfil 2010/2011, mejor foto periodística del año. Premio a la Excelencia Periodística 2001 (otorgado por Sociedad Interamericana de Prensa). Premio a la mejor labor fotoperiodística del año, 2011, 1999, 1998 y 1992 (otorgado por ADEPA). Premio a la Fotografía Periodística del
\end{abstract}


diario La Nación (1989). Becario del Fondo Nacional de las Artes, 1997 y de la Fundación Nuevo Periodismo Iberoamericano, 2003. Es autor del libro de edición independiente "ADN, historias de aparecidos". 